\title{
THE LINK BETWEEN PRODUCTIVITY AND LABOUR SHARE - THE CASE OF NORTH MACEDONIA AND SLOVENIA
}

\author{
Borce Trenovski, PhD \\ Faculty of Economics - Skopje, Ss Cyril and Methodius University \\ Borce.Trenovski@eccf.ukim.edu.mk \\ Kristijan Kozeski, MSc \\ Faculty of Economics - Skopje, Ss Cyril and Methodius University \\ kozeski@eccf.ukim.edu.mk \\ Gunter Merdzan, MSc \\ Faculty of Economics - Skopje, Ss Cyril and Methodius University \\ gjunter.merdzan@eccf.ukim.edu.mk
}

\begin{abstract}
The large divergence between productivity and workers' incomes has been becoming a reality in most countries, not just in the United States after 1980s, where labour productivity grew faster than real wages and employment. The breakdown according to Brynjolfsson and McAfee (2014) is due to technological progress, according to Bivens and Mishel (2015) the growing inequality and according to Baker (2007) the declining labour share in GDP. The main goal of this paper is to find out if the global trend of "The Great Decoupling" between productivity and labour share is a real process in the case of the countries analyzed from the Southeast Europe region. Given that Slovenia is among the most developed countries, while North Macedonia belongs to the group of developing countries that in these stages of development rely on foreign capital and cheap labour, we examine whether the process of "The Great Decoupling" between productivity and labour share is a reality in both countries. From the analysis of the trend of the movement of the average labour productivity of these two countries, it can be concluded that in both countries there is a trajectory of the movement of the labour productivity. Also, from the trend of the movement of the share of labour income and labour productivity in the case of Slovenia and North Macedonia it can be concluded that they indicate the existence of a large gap, i.e. divergence in the trajectory of motion. Also, the gap between labour productivity and the share of labour income in GDP on the example of North Macedonia, if compared to the example of Slovenia is of lower intensity. Finally, based on the results obtained from the conducted econometric analysis, we determine whether there is a need for further research or the phenomenon is a temporary deviation in the dynamics of the gap between labour share and labour productivity.
\end{abstract}

Keywords: The Great Decoupling, Labour Productivity, Labour Share, Comparative Analysis, Regression Analysis.

JEL classification: C13, E24, J24.

http://doi.org/10.47063/EBTSF.2020.0020

http://hdl.handle.net/20.500.12188/9718 


\section{INTRODUCTION}

One of the most significant trends that began to shape the world since the 1980s was the phenomenon of the declining labour share of income, i.e. the share of national income allocated to wages (labour). This meant that most of the benefits from productivity growth, especially in the mid-1990s, did not reflect the standard of living of most workers. This issue of "divergence between labour productivity and real wage growth/compensation", or as Brynjolfsson and McAfee (2014) prefer to say "The Great Decoupling", is the subject of growing academic and political debate in the United States of America (USA), where a large number of American workers experience wage stagnation (Stansburry \& Summers, 2018). A numerous study in this topic show, the divergence between labour productivity and compensation is becoming a reality in much of Europe and other countries. But, very interesting part is that some of the papers show that this phenomenon occurs not only in capital-intensive industries and countries but also in labourintensive countries such as China, India, Mexico, etc. (Karabarbounis \& Neiman, 2013). In this paper, for the first time, an attempt is made to examine this phenomenon on the case of North Macedonia and Slovenia, two countries in the Southeast Europe (Balkans) that had belonged to the former Socialist Federal Republic of Yugoslavia (SFRY), and have very close political and economic relations. Given that Slovenia was the most developed Yugoslav republic, and is still the most developed country in the region of Southeast Europe, a member of the European Union (EU) while North Macedonia is a developing country aspiring to become an EU member. The aim in this paper is to examine whether the global trend of divergence between growth in labour productivity and compensation persists in the case of these countries and where that divergence is more explicit.

Some of the previous empirical research conducted to determine the relationship between labour productivity and real wages/compensation differ in their nature and conclusions. The fact that increased labour productivity is considered a key driver of economic growth has prompted researchers around the world to make great efforts to determine the relationship between labour productivity and worker' incomes (workers' compensation, wages or labour share), announcing the standard economic theory of labour productivity and workers' incomes. The theory is that labour markets tend to balance real wages and productivity. Productivity above real wages moves wages up (because firms demand more labour), and in times of low capacity utilization and low productivity, labour demand is expected to fall, pushing real wages down. In analyzing the differences between productivity and wages, factors such as low unionization rates, the shadow economy, informal labour markets and so on can be considered. Also, numerous methodological issues such as wage deflation procedures real wage indicators, labour productivity indicators, and labour and capital shares of national income can cause changes in the analysis (Škare \& Škare, 2017).

The main goal of this paper is to find out if the global trend of "The Great Decoupling" between productivity and labour share is a real process in the case of the countries analyzed from the Southeast Europe region. Given that Slovenia is among the most developed countries, while North Macedonia belongs to the group of developing countries, we examine whether the process of "The Great Decoupling" between productivity and labour share is a reality in both countries. Finally, based on the results obtained from the conducted econometric analysis, we determine whether there is a need for further research or the phenomenon is a temporary deviation in the dynamics of the gap between labour share and labour productivity.

Specifically, this paper analyzes two issues. First, whether and to what extent the growth

of the part of the income allocated to workers is systematically related to the growth in labour 
productivity in the last 3-4 decades. Second, whether the gap between workers' incomes and productivity growth increases or decreases over time and what happens in the analyzed countries from the Southeast region. While, finding the answers to these questions will allow us to better understand the three currently prominent economic and political topics (Theodoropoulou, 2019): (1) What causes income inequality the most? (2) How can the fragile recovery and stagnant growth rates after the Great Recession of 2008 be strengthened in the analyzed countries and beyond in Europe?

This paper is structured as follows. After the introductory part, in the literature review section, we try to present the most significant papers in this area and determine whether they confirm the phenomenon of "The Great Decoupling" on the case of different countries or groups of countries. Then we analyze the dynamics between labour productivity and the labour share in selected countries. In the methodology section, we present the details of the methods of scientific research used to analyze the relationship between labour productivity and the income of workers on the case of the selected countries from the Southeast Europe region. In the last part of the paper, the obtained results from the analysis are commented on and discussed. While the conclusion part discusses the theoretical and practical implications of the study, the possibility for future research and recommendations for policy makers are given.

\section{LITERATURE REVIEW}

The link between labour productivity and workers' incomes is an essential part of the labour market and the economy as a whole. In the standard economic theory, the relationship between labour productivity and income is described as a positive relationship, which coverages and oscillates around unit elasticity. Technological progress increases productivity, which according to the theoretical postulates of the labour market leads to an increase in workers' incomes. The increase in marginal labour productivity as a result of technological development puts pressure on labour demand and ultimately causes an increase in labour income as a relative proportion of GDP and the general level of wages. On the other hand, workers' wages are the main source of income for an average household, growing incomes stimulate the average purchasing power and consumption of households, leading to future economic growth (Patra \& Nayak, 2012). Furthermore, whenever labour productivity is above wage levels, firms increase their labour demand by raising wages and reducing productivity. Wage levels that rise above efficiency wages, that is, wages that grow faster in terms of productivity, slow down labour demand, putting downward pressure on wages. The dynamics of the relationship between the three variables, income-productivity-employment determines the behavior of firms, because firms operating in industries with rising wages above the level of productivity cannot keep up with the current level of output and employment. The only way to break this vicious circle is to invest in technological improvement followed by increasing domestic investment and reviving productivity (Škare \& Škare, 2017).

Stansburry and Summers (2018), summarize three possible broader explanations for the apparent divergence of workers' incomes from labour productivity. First, there is a complete disconnect between the growth of workers' incomes from labour productivity, which means that the growth of productivity no longer leads to further wage growth. Second, there is still a link between the two variables, but other structural factors such as reducing union power and the workforce have weakened this link by reducing to what extent productivity gains are transformed into higher wages. Third, the link between productivity and wages still exist, but other factors, such as technological change, have put downward pressure on wages. 
Obtaining a clearer picture of whether the relationship between labour productivity growth and labour income growth as a relative proportion of GDP is still strong and significant, facilitates the process of assessing whether certain policy recommendations will bear fruit or not. For example, the European Commission's 2017 Annual Growth Survey highlights that "real wage growth as a result of increased productivity is important for reducing inequalities and maintaining high standards' of living" (European Commission, 2017a). Whereas, in its autumn forecasts for 2017, it suggested that "significant and structurally higher wage growth will require a trend reversal in low labour productivity growth" (European commission, 2017b). The assumption here is that, if successful, policies that promote faster labour productivity growth, for example by encouraging technological advancement, should be scaled down to produce labour wage gains.

Blanchard and Giavazzi (2003) argue that deregulation in product and labour markets decreased labour shares and increased unemployment in Europe in the 1980s. Bentolila and SaintPaul (2003) also focus on the variability on labour shares over the medium run, including the large declines seen during the 1980s in Western Europe. Harrison (2002), using data from the United Nations (UN) finds a decreasing trend in the labour share of poor countries but an increasing trend in rich countries for 1960-1997. Karabarbounis and Neiman (2013), in their research prove that roughly half of the observed decline in the labour share can be explained by the declining relative price of investment goods due to advances in the information technology and the computer age. Previous studies on the relationship between income and labour productivity of Bivens and Mishel (2015), Lawrence (2016), and Stansburry and Summers (2018) have focused on the United States, the study of Pessoa and Van Reenen (2012) has focused on United Kingdom and the study of Pasimeni (2018) has focused on EU. Pasimeni (2018), examines this issue for 34 advanced economies, including the EU, through the use of macro-panel data analysis. As the author himself admits in the conclusion of his paper, however, is aggregate panel approach probably obscures the considerable heterogeneity between countries. The wide diversity of wage-setting institutions across the EU is one of the several factors that suggest that such heterogeneity is likely to be sufficiently important to warrant a country-by-country investigation. Stansburry and Summers (2018) extended their country-by-country analysis to individual G7 member states, including EU member states France, Germany and Italy.

A study of Trenovski, et al. (2019) conducted in 2019 in some EU countries concluded that the relationship between labour productivity and real compensation within high-income countries, which are also classified as the member states that joined the EU before 2004, on average there is an evident synchronized movement of labour productivity per working hour and real compensation per working hour of workers. However, it should be noted that this group of countries, in some cases there is a deviation in the trend of movement in labour productivity per hour worked and the real compensation per hour of workers. In the case of Germany, France, Luxembourg, and Sweden, e.g. the increase in real hourly workers' compensation is faster than the increase in hourly labour productivity. On the other hand, the case of Ireland should be mentioned, where starting from 2012, labour productivity has increased more intensively, while the real compensation of workers has stagnated, which is the most striking example of the existence of the phenomenon of "The Great Decoupling" in developed countries.

\section{RESEARCH METHODOLOGY}

The examined model is acceptable if the following test and evaluation results are obtained (Bucevska, 2016): (1) There is no indication that the model specification is wrong; (2) The regression is statistically significant; (3) All estimated parameters are statistically significant and 
have an appropriate sign; (4) There should be no autocorrelation, heteroskedasticity in the model and the residuals should be normally distributed.

Once the model has been specified, the next step is to estimate the regression models between labour productivity and workers' incomes for both countries using the ordinary least squares (OLS) method. For the purposes of this analysis, the double logarithmic regression model is used. The theoretical regression function of the model with two variables is as follows:

$$
Y_{i}=b_{0}+b_{1} X_{i}+\hat{\mathrm{u}}_{i},(1)
$$

where $b_{0}$ and $b_{1}$ are the estimated intercept and slope coefficients of the regression, respectively. For us, the coefficient $b_{1}$ is important, which shows how much the average share of GDP allocated for workers will increase as a result of productivity growth. After the estimation, we comment and compare the magnitudes and signs of the $b_{1}$-coefficients for the examined countries and their significance.

We also test he F-statistics in parallel to see if the overall model is (un)significant. We also check the coefficient of determination $-\mathrm{R}^{2}$ which indicates how much of the variation in the model is explained by the variables of the model. To determine the degrees of linear dependencies between variables, we calculate the coefficients of simple correlations and comment on them. We are also testing multicollinearity because many people think that an absolute value of $r$ higher than 0,80 is already sign of strong multicollinearity. Through the Breusch-Pagan-Godfrey test we test the heteroskedasticity, and to test the normal distribution of the residuals we use the Jarque-Bera test.

\section{RESULTS}

Although according to conventional economic thought the increase in labour productivity is followed by a proportional increase in workers' incomes, empirical results indicate that such an assumption is almost unrealistic. The trend of labour productivity and labour share of the example of Slovenia and North Macedonia is shown in Figure 1. The trends of labour share and labour productivity in the case of Slovenia indicate a large gap in their trend. Namely, the trend of the movement of the share of labour income in the GDP can be divided into two sub-periods. First, within the period 1995-2007, although a weak downward trend is observed, which reaches the lowest value in 2007, 86 index points. Second, within the period 2008-2017 it can be concluded that the trend of movement of this magnitude is not characterized by larger fluctuations, i.e. is characterized by a certain degree of stability and consistency in its movement, to reach 87.5 index points at the end of 2017. On the other hand, throughout this period, on average, labour productivity has increased. It should be noted that the period 2009-2010, under the influence of the financial crisis that affected most of the countries in the world, also in Slovenia economic activity begun to decline. On the other hand, from the trend of the case of North Macedonia it can be concluded that the existence of a gap, i.e. the so-called divergence in the trends of labour productivity and the labour income share is evident. It should be emphasized that this gap on the example of North Macedonia, if compared to the example of Slovenia is of lower intensity. By the same analogy, the trend of the movement of labour productivity and the income of workers on the example of North Macedonia can be divided into two periods. First, within the period 1995-2004 where the movement, although it has a downward trend, is of low intensity. Second, the time period 2005-2017 where there is a more intense decline in the labour income share. 
Figure 1: Labour productivity and labour compensation of Slovenia and North Macedonia for a period 1995-2017 $(1995=100)$

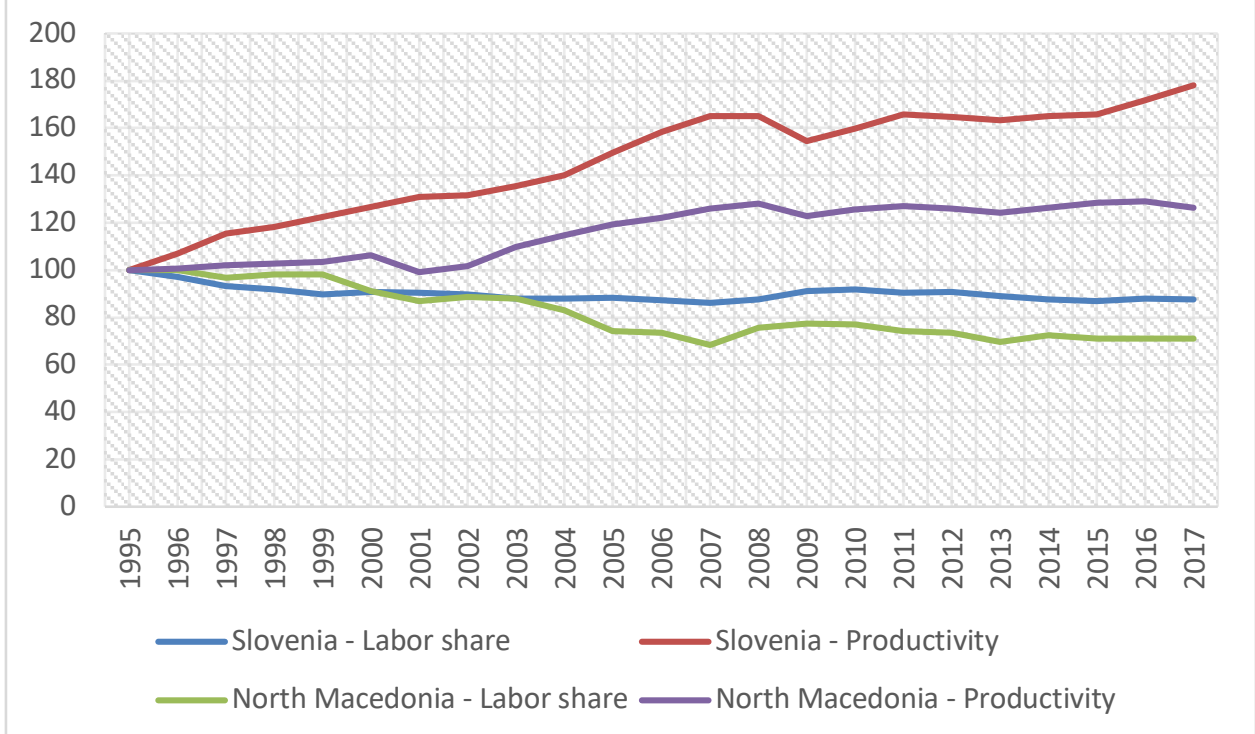

(Source: Author's calculation based on Penn World Table data.)

In the period from 1995 to 2000, the labour income share of the example of Slovenia and North Macedonia did not show significant differences. This proportion ranges from $69 \%$ in North Macedonia to $73 \%$ in the case of Slovenia. However, after 2000, the movement trends do not follow the same trajectory. The labour share of the example of North Macedonia decreased significantly in the period from 2001 to 2007. Namely, in 2001 this ratio was $60 \%$, while in 2007 it was $47 \%$, which indicates a decrease of 13 percentage points. After reaching the historically lowest value of the labour share in 2007 from 2008 to 2010, this proportion increased modestly, i.e. increased to $53 \%$ in 2010 . In the period from 2011 to 2017 , on average it recorded a downward trend and in 2017 it reached 49\%. Compared to 2000, the labour share of the case of the Republic of North Macedonia decreased by 14 percentage points. Regarding the example of Slovenia, it can be concluded that in the period from 1995 to 2009 the movement of labour share is characterized by a downward trend and it decreased from $73 \%$ in 1995 to $63 \%$ in 2007 . In the period from 2008 to 2017, on average, the trend of the movement can be concluded to be positive, and this proportion in 2017 reaches $64 \%$.

The results of the descriptive analysis indicate that although for a long time the labour share was considered stable, the trend of the example of Slovenia and North Macedonia confirms the widespread fact that in the last few decades there has been a significant change in the functional distribution of income, recording a significant increase in capital income, and decrease of the labour income. In order to analyze the causal relationship between the labour share and labour productivity growth, a regression analysis was conducted, the results of which are shown in Table 1. Values of $\beta$ coefficient indicate the relationship between labour productivity growth and movement on the labour share. On the example of Slovenia and the example of North Macedonia, the value of the coefficients is negative. The value of the $\beta$ coefficient of -0.764105 on the example of North Macedonia indicates the fact that the increase of labour productivity by $1 \%$ results in a decrease of the labour share of $0.76 \%$. On the other hand, in the example of Slovenia, the $\beta$ coefficient is -0.111146 , which indicates the fact that the increase in labour productivity by $1 \%$, leads to a decrease in the labour share of $0.11 \%$. The value of the coefficients in both countries 
indicates a negative relationship between the increase in labour productivity and the share of labour income in GDP, however this relationship is much stronger on the example of North Macedonia compared to the case of Slovenia. From this it can be concluded that the increase in labour productivity leads to an increase in the gap in the distribution of total income between the factors of production, i.e. between labour and capital on the example of North Macedonia compared to Slovenia. In other words, on average, an increase in labour productivity, although it results in an increase in total national income, is not sufficiently transferred to workers in the form of wages, bonuses and compensations.

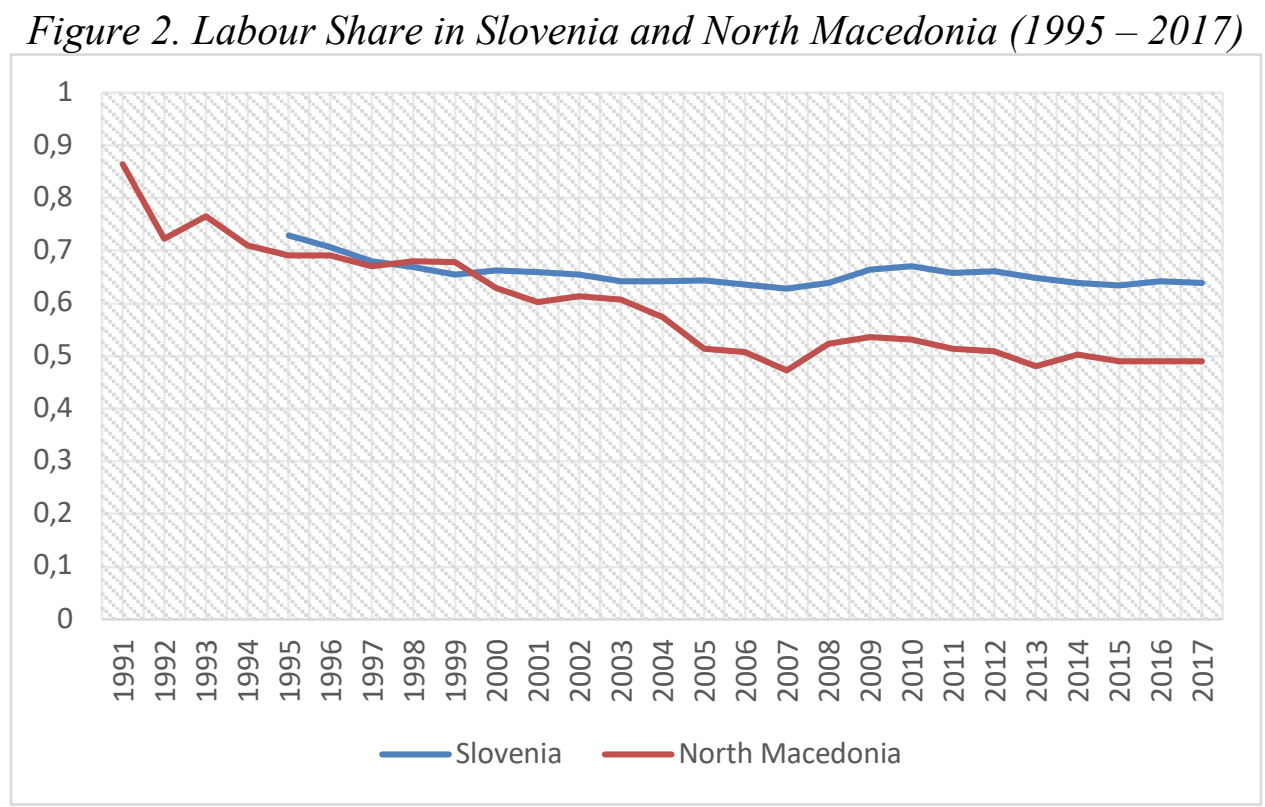

(Source: Penn World Table.)

On the other hand, in order to supplement the results of the analysis and determine the degree of robustness of the regression models, the table shows the coefficients of determination of the example of both countries. On the example of North Macedonia $\mathrm{R}^{2}$ is $53 \%$, which indicates a good fit of the model, i.e. indicates the fact that $53 \%$ of the changes in the labour share can be explained by changes in labour productivity. On the other hand, $\mathrm{R}^{2}$ on the example of Slovenia is $60 \%$ which indicates the fact that $60 \%$ of the changes in the labour share are affected by changes in labour productivity, while the remaining $40 \%$ are influenced by other economic and non-economic factors. In this regard, it should be noted that workers' incomes, despite the economic component, they also contain a social component, i.e. despite market forces, other non-market factors have a certain influence in their formation (labour legislation with a focus on legal minimum wage, social transfers, benefits that workers enjoy as a result of employment health insurance, various allowances, bonuses and bonuses) that are a result of employment but are not recorded as income. 
Table 1: Results from econometrics analysis

Country $\quad \beta_{1}$ coefficient $\quad$ R2 - Coefficient of determination Time period

\begin{tabular}{llcc}
\hline North Macedonia & $-0,764105^{*}$ & 0,534954 & $1992-2017$ \\
\hline Slovenia & $-0,111146^{*}$ & 0.601335 & $1995-2017$ \\
\hline \multicolumn{3}{r}{$(*$ level of significance 1\%, **level of significance 5\%) }
\end{tabular}

\section{CONCLUSION}

Debates and research related to labour productivity and workers' incomes in the last few decades have been a field of interest among the academic community around the world. Part of such research focuses on the relationship between labour productivity and workers' wages, the actual compensation transferred to workers, and labour income as a relative proportion of GDP.

Research analyzing the relationship between labour productivity and workers' incomes, conducted in developed and developing countries around the world, indicates that the empirical reality is to some extent inconsistent with standard economic theory of worker productivity and income. On the other hand, the phenomenon of the so-called "Great Decoupling" is becoming an objective reality in many countries, especially after 1980. This phenomenon is caused by the rapid rise in labour productivity, and the inability of workers' incomes to connect with it. Such tendencies have been the basis for growing inequality in income distribution and declining share of labour income in Gross Domestic Product.

In this paper, a comparative analysis of the relationship between labour productivity and the share of labour income in the Gross Domestic Product (GDP) of Slovenia and North Macedonia is made.

From the analysis of the trend of the movement of the average labour productivity of these two countries, it can be concluded that in both countries there is a trajectory of the movement of the labour productivity. Also, from the trend of the movement of the share of labour income and labour productivity in the case of Slovenia and North Macedonia it can be concluded that they indicate the existence of a large gap, i.e. divergence in the trajectory of motion. It should be noted here that the period 2009-2010, under the influence of the financial crisis that affected most of the countries in the world, economic activity and in the case of Slovenia saw a certain degree of decline. On the other hand, from the trend of the case of North Macedonia it can be concluded that the existence of a gap, i.e. the so-called divergence in the trends of labour productivity and the share of labour income in tasty income is evident. Also, the gap between labour productivity and the share of labour income in GDP on the example of North Macedonia, if compared to the example of Slovenia is of lower intensity.

In the period from 1995 to 2000 , the share of labour income in the total income of the example of Slovenia and North Macedonia did not show significant differences. This proportion ranges from $69 \%$ in North Macedonia to $73 \%$ in the case of Slovenia. However, after 2000, the movement trends do not follow the same trajectory. The share of labour income in the total income of the example of North Macedonia decreased significantly in the period from 2001 to 2007. Namely, in 2001 this ratio was $60 \%$, while in 2007 it was $47 \%$, which indicates a decrease of 13 percentage points. In the period from 2011 to 2017, on average it recorded a downward trend and in 2017 it reached $49 \%$. Compared to 2000, the share of labour income in the total income of the case of the Republic of North Macedonia decreased by 14 percentage points. Regarding the 
example of Slovenia, it can be concluded that in the period from 1995 to 2009 the movement of Labour income in total income is characterized by a downward trend and it decreased from $73 \%$ in 1995 to $63 \%$ in 2007 . In the period from 2008 to 2017 , on average, the trend of the movement can be concluded to be positive. This proportion in 2017 reaches $64 \%$.

The results of the econometric analysis, above all the value of the $\beta$ coefficient of -0.764105 on the example of North Macedonia indicate the fact that the increase of labour productivity by $1 \%$ results in a reduction of the share of labour income in total income of $0.76 \%$. On the other hand, in the example of Slovenia, the $\beta$ coefficient is -0.111146 , which indicates the fact that the increase in labour productivity by $1 \%$, leads to a decrease in the share of income in total income of $0.11 \%$. In this regard, it should be noted that workers' incomes, in addition to having an economic component, they also contain a social component, i.e. in addition to market forces, other non-market factors have a certain influence in their formation (labour legislation with a focus on legal minimum wage, social transfers, benefits that workers enjoy as a result of employment (health insurance, various allowances, bonuses and bonuses) that are a result of employment but are not recorded as income.

\section{REFERENCES}

Baker, D., (2007). The Productivity to Paycheck Gap: What the Data Show, London: Center for Economic and Policy Research (CEPR).

Bentolila, S. \& Saint-Paul, G., (2003). Explaining Movements in the Labor Share. The B.E. Journal of macroeconomics, 3(1).

Bivens, J. \& Mishel, L., (2015). Understanding the Historic Divergence between Productivity and a Typical Worker's Pay: Why it Matters and Why it's Real, Washington, DC: Economic Policy Institute.

Blanchard, O. \& Giavazzi, F., (2003). Macroeconomic Effects of Regulation and Deregulation in Goods and Labor Markets. The Quarterly Journal of Economics, 118(3), pp. 879-907.

Brynjolfsson, E. \& McAfee, A., (2014). The Second Machine Age: Work, Progress, and Prosperity in a Time of Brilliant Technologies. New York: W. W. Norton \& Company, Inc..

Bucevska, V., (2016). Econometrics with Application in EViews. 2nd ed. Skopje: Faculty of Economics - Skopje.

European Commission, (2017a). Annual Growth Survey 2018: Communication from the Commission to the European Parliament, the Council, the European Central Bank, the European Economic and Social Commitee, the Committee of the Regions and the European Investment Bank, Brussels: s.n.

European commission, (2017b). European Economic Forecast, Brussels: s.n.

Harrison, A., (2002). Has Globalization Eroded Labor's Share? Some Cross-Country Evidence, s.l.: University of California at Berkeley, Working Paper.

International Labour Organization, (2012). Global Wage Report 2013/13: Wages and Equitable Growth, Geneva: s.n.

Karabarbounis, L. \& Neiman, B., (2013). The Global Decline of the Labor Share. National Bureau of Economic Research, Working Paper No. 19136.

Lawrence, R. Z., (2016). Does Productivity Still Determine Worker Compensation? Domestic and International Evidence. In: M. R. Strain, ed. The US Labor Market: Questions and Challanges for Public Policy. Washington, DC: American Enterprise Institute.

Pasimeni, P., (2018). The Relation between Productivity and Compensation in Europe. Publications Office of the European Union, Discussion Paper 079. 
Patra, S. P. \& Nayak, S. R., (2012). A Theoretical Study on the Relationship between Wages and Labor Productivities in Industries. International Journal of Economics and Research, 1(3), pp. 157-163.

Pessoa, J. P. \& Van Reenen, J., (2012). Decoupling of Wage Growth and Productivity Growth? Myth and Reality. Centre for Economic Performance, Discussion Paper No. 1246.

Škare, M. \& Škare, D., (2017). Is the Great Decoupling Real?. Journal of Business economics and Management, 18(3), pp. 451-467.

Stansburry, A. \& Summers, L., (2018). Productivity and Pay: Is the link broken?. The National Bureau of Economic Research, Working Paper No. 24165.

Theodoropoulou, S., (2019). Convergence to fair wage growth? -Evidence from european countries on the link between productivity and real compensation growth, 1970-2017-. European Trade Union Institute, Working Paper 2019.07.

Trenovski, B., Tashevska, B., Kozheski, K. \& Merdzan, G., (2019). The Link between Productivity and Labor Compensation in Selected Central and Southeast European Countries. Banja Luka, University of Banja Luka. 